\title{
CONFUCIANISM AND PREFERENCES: \\ EVIDENCE FROM LAB EXPERIMENTS IN TAIWAN AND CHINA
}

\author{
Elaine M. Liu \\ Juanjuan Meng \\ Joseph Tao-yi Wang \\ Working Paper 19615 \\ http://www.nber.org/papers/w19615 \\ NATIONAL BUREAU OF ECONOMIC RESEARCH \\ 1050 Massachusetts Avenue \\ Cambridge, MA 02138 \\ November 2013
}

We thank Dan Benjamin, Colin Camerer, Xi Chen, Aimee Chin, Angus Deaton, Benjamin Ho, Nathan Nunn, Chunlei Yang, Ying Zhang, seminar participants at Chapman University and conference participants at the NBER conference on Culture and Religion, ESA and NEUDC for helpful discussion and comments. We thank editor and anonymous referees for comments. Elaine M. Liu thanks Chiang Ching-kuo Foundation for financial support. Joseph Tao-yi Wang thanks National Taiwan University and the National Science Council of Taiwan (NSC 99-2410-H-002-060-MY3, NSC 102-2628-H-002-002-MY4) for financial support. The views expressed herein are those of the authors and do not necessarily reflect the views of the National Bureau of Economic Research.

At least one co-author has disclosed a financial relationship of potential relevance for this research. Further information is available online at http://www.nber.org/papers/w19615.ack

NBER working papers are circulated for discussion and comment purposes. They have not been peerreviewed or been subject to the review by the NBER Board of Directors that accompanies official NBER publications.

(C) 2013 by Elaine M. Liu, Juanjuan Meng, and Joseph Tao-yi Wang. All rights reserved. Short sections of text, not to exceed two paragraphs, may be quoted without explicit permission provided that full credit, including $\odot$ notice, is given to the source. 
Confucianism and Preferences: Evidence from Lab Experiments in Taiwan and China Elaine M. Liu, Juanjuan Meng, and Joseph Tao-yi Wang

NBER Working Paper No. 19615

November 2013

JEL No. C91,Z10

\section{ABSTRACT}

This paper investigates how Confucianism affects individual decision making in Taiwan and in China. We found that Chinese subjects in our experiments became less accepting of Confucian values, such that they became significantly more risk loving, less loss averse, and more impatient after being primed with Confucianism, whereas Taiwanese subjects became significantly less present-based and were inclined to be more trustworthy after being primed by Confucianism. Combining the evidence from the incentivized laboratory experiments and subjective survey measures, we found evidence that Chinese subjects and Taiwanese subjects reacted differently to Confucianism.

Elaine M. Liu

Department of Economics

University of Houston

Houston, TX 77204

emliu@uh.edu

Juanjuan Meng

Department of Applied Economics

Guanghua School of Management

Rm. 323, Hall 2

Peking University

Beijing 100871, China

jumeng@gsm.pku.edu.cn
Joseph Tao-yi Wang

National Taiwan University

Department of Economics

Taipei, Taiwan

josephw@ntu.edu.tw 
"The power behind the recent surge in Asia's economy may have developed from the tenets of one of that continent's earliest philosophers."

Hofstede and Bond (1988)

\section{Introduction}

Confucian values are widespread throughout East Asia--China, Taiwan, Hong Kong, Singapore, South Korea, and Japan. Scholars have long hypothesized that that Confucian values affect social norms, influence individual decision making, and possibly contribute to economic growth. In particular, the Confucian emphasis on the accumulation of human capital, perseverance, and a future orientation can be key components of economic growth. (See Hofheinz \& Calder,1982; Hofstede \& Bond, 1988; Dai, 1989; Rozman, 1992; Ornatowski, 1996; Chan, 1996; Lam, 2003; Liang, 2010). ${ }^{1}$ Surprisingly, however, little has been done in the way of empirical research to test these claims, and most of that work has been ethnographic in nature.

Whether there is a causal relationship between Confucianism and economic outcomes is extremely difficult to determine. This study takes the first step in probing this relationship with lab experiments. We adopt the priming method to investigate how Confucianism affects individual behaviors. To our knowledge, this is the first paper that primes the salience of Confucianism.

The priming method has been widely used in psychology and marketing. (Turner, 1985; Macrae \& Johnston, 1998; Dijksterhuis \& Bargh, 2001; Wheeler, Jarvis, \& Petty, 2001). In recent years, several economic studies, including Afridi, Li, and Ren (2012), Benjamin et al. (2010, 2012), have used this technique to study the impact of religion, race, and group identities. In one interesting example where cultural prime is used, Westernized Hong Kong-Chinese subjects were primed with either American or

\footnotetext{
${ }^{1}$ Another line of studies suggests that Confucianism may be a barrier to capitalism because of the strict hierarchy of the social order and the avoidance of individual confrontation with the world. For example, Max Weber suggested that enthusiasm for action is rare in Confucianism and that active pursuit of wealth is unbecoming to proper Confucians (Bendix, 1960; Chung, Shepard \& Dollinger 1989).
} 
Chinese culturally-laden icons, then they were shown a picture with one fish swimming ahead of four others and were asked to describe what they see (Hong, Chiu, \& Kung, 1997; picture first used in Morris Nisbett, \& Peng, 1995). When they were primed with American icons such as an American flag, subjects were more likely to describe that the lone fish was leading the others. Whereas subjects being primed with Chinese primes were more likely to describe that the lone fish was being chased by the other fish. ${ }^{2}$

In this study, subjects in the experiments were randomly assigned to receive Confucius-prime or neutral-prime. The primes were designed to introduce variation in the salience of Confucianism, so that the normally dormant aspects of the Confucian values may be temporarily activated by the Confucian prime. After randomly manipulating the salience of Confucianism to our subjects, we elicited subjects' risk preferences (risk aversion, loss aversion), time preferences (present bias and discount factor), and trust and trustworthiness using an incentive-compatible protocol. Others have shown that these individual preferences play a central role in economic outcomes (Shaw, 1996; Knack and Keefer 1997; Laibson, 1997; La Porta et al. 1997). If there is any difference in their outcomes between these Confucius-prime and neutral-prime groups, we can attribute it to their reaction to the Confucius prime.

Our findings suggest that subjects became more trustworthy and risk loving, exhibited less present bias, and, interestingly, became more impatient when they were exposed to the Confucius prime. Our evidence also showed that subjects in Taiwan and in China reacted differently to the Confucius prime. In contrast to the control group, subjects in China became more risk loving, less loss averse, and more impatient, behaviors not in alignment with Confucian values. The subjects in Taiwan became less present-biased than the control group and also mainly drove the more trustworthy results, in accord with Confucian values. We performed validation checks of our priming instruments by asking subjects to rank on a scale of 1 to 10 how much they agreed with each of four different belief systems: Confucianism, rationalism, Eastern religion, and Western religion. We found that Chinese subjects, but not subjects in

\footnotetext{
${ }^{2}$ This paper is also related to another line of literature discussing why culture matters in economics outcomes, some papers in the literature include Inglehart and Baker (2000), Guiso et al. (2006), Fernandez (2011), and Gorodnichenko \& Roland (2013).
} 
Taiwan, who were primed on Confucianism were more likely to rank Confucius lower and agreed less with Confucian values than the control group did.

There are many possible explanations for the observed differences in the priming effect across the two schools. Our regression analysis excludes background differences in the two samples as the main reason for the different reactions to Confucius prime. One important possibility is the different historical experiences in regard to Confucian values in the two places.

Although Confucian values have long influenced a number of Asian countries, Confucius was excoriated as a political swindler and Confucian values were denounced during China's Cultural Revolution (1967-1976) (Lu, 2004). Sociologists now suggest that as a result, Confucian tradition is better preserved and practiced today in Asian countries other than China, for example, in Taiwan (Ip, 2009). Nevertheless, some researchers, for example Herman Kahn and Geert Hofstede, have suggested that cultural traits can be rather sticky, and therefore difficult to change (for more discussion see Hofstede \& Hofstede, 2005). ${ }^{3}$ Most Taiwanese trace their ancestry to China, share the same language, and have similar culture today as in China. In addition, Confucian values have been passed down in Taiwan from parents to children and from teachers to students. Based on our observation of Taiwanese subjects, we can conclude that the Confucianism cultural traits have persisted. However, our study also suggests that young generations of Chinese and of Taiwanese have diverging reactions to Confucianism. Whether this interruption and discourse of Confucian belief in China is caused by Cultural Revolution is beyond the scope of this paper, and it is a topic for future research. ${ }^{4}$

\footnotetext{
${ }^{3}$ Some economic papers suggest that certain traits can be quite sticky. For example, Nunn and Wantchekon (2011) suggest that although the slave trade took place in Africa more than 400 years ago, it has a long-lasting impact on mistrust even today. Similarly, Alesina, Guiliano, and Nunn (2013) find that beliefs about women's roles in different societies today can be traced to different agricultural practices hundreds of years ago.

${ }^{4}$ The subjects in our sample were too young to have had direct exposure to Cultural Revolution, but their parents would have experienced the Cultural Revolution. If their views of Confucius have changed as a result of the Cultural Revolution, it suggests that the Cultural Revolution has had a long-lasting impact that extends beyond the generation that experienced it directly.
} 
The rest of the paper is organized as followed, Section 2 presents some background on Confucianism and our hypothesized links between preferences and Confucianism, section 3 sets out the experiment, section 4 discusses the results, and section 5 concludes.

\section{Background on Confucianism and Hypothesized Links between Confucian Values and Economic}

\section{behavior}

Confucianism is often regarded as advocating conservative behavior in society; therefore, we hypothesized that the primary effect of Confucianism priming would be to encourage more risk aversion and loss aversion behaviors. To our knowledge, Confucius himself did not directly say whether taking a risk should be encouraged or not, but there are some famous quotes from Mencius, the second most important person in Confucianism and one of its principal interpreters, that can be viewed as encouraging risk aversion--for example, "One who understands destiny will not stand beneath a tottering wall."5 Confucian values also emphasize the role of individuals within a society and their relationship to others. For example, a male can view himself as a son, a brother, a husband, and a father but rarely as an autonomous individual (Hwang, 1987; Gao, 1998). Based on this theme of an individual's role in a group, scholars such as Tse (1996) and Yeh and Xu (2010) suggest that individual risk-taking behavior can be regarded as challenging a group's interest and even existence, and thus is discouraged. ${ }^{6}$ As for loss aversion, extending what Yeh and Xu (2010) suggest, incurring loss can also threaten a group's harmony.

Being more future oriented is a central theme in Confucius teaching and captured in many wellknown Confucius sayings - for example, "Impatience over trivial things may ruin important pursuits,"

\footnotetext{
${ }^{5}$ The quote is from the book The Mencius.

${ }^{6}$ Alternatively, economic studies such as Barr and Genicot (2008) find that the availability of a risk-sharing arrangement can increase individual risk-taking behavior in a lab experiment. It is also possible that when the salience of Confucianism reminds individuals of their role in a group and their risk-sharing network, the subjects in the Confucian prime group may take more risks in a lottery. However, we think this effect is secondary.
} 
and, "If a man takes no thought about what is distant, he will find sorrow near at hand."7 Thus, we would predict that subjects should become more patient after being primed. ${ }^{8}$

In the case of trust and trustworthiness, according to Koehn (2001), one distinct feature of Confucian thinking is that the virtue of trustworthiness is more important than actual trust. For example, in The Analects of Confucius there are sayings like, "I do not know how a man without truthfulness is to get on." and, "I daily examine myself on three points:- - whether, in transacting business for others, I may have been not faithful; - - whether, in interaction with friends, I may have been not been trustworthy;whether I may have not mastered and practiced the instructions of my teacher." We predicted that subjects would become more trustworthy after being primed. Given that the Confucian values put a great emphasis on trustworthiness, it is natural to trust those who follow Confucian practice as well (Tan and Chee, 2005). Therefore, we also predicted that subjects would become more trusting after being primed. However, the priming effect on trust may not as salient as the priming effect on trustworthiness.

\section{Experimental Design}

This study drew subjects from the student pools of National Taiwan University (NTU) and Peking University (PKU) by soliciting students on campus through flyers and e-mails. ${ }^{9}$ Our final study had 380 subjects: 195 NTU students and 185 students from PKU. A total of nineteen experimental sessions were carried out with paper and pencil from September 2012 to April 2013. When subjects arrived at an experimental session, their seats were assigned randomly. They were instructed not to communicate with one another during the experiment and given oral instructions for the general rules and written instruction for each part of the experiment (the full experimental protocol is in the web appendix).

\footnotetext{
${ }^{7}$ Both quotes are from the book The Analects of Confucius. The translations of The Analects of Confucius texts used in this paper are from Legge (1893).

${ }^{8}$ In a recent work, Liang (2010) develops a general equilibrium model with specified Confucian parameters. Under the assumption that countries exposed to Confucian values have lower discount rates, he calibrates the model to assess the quantitative importance of these cultural effects and to examine their implications for the future evolution of these economies.

${ }^{9}$ NTU subjects recruited through the online recruiting system of Taiwan Social Sciences Experimental Laboratory (TASSEL).
} 
Subjects were told the total number of games they would participate in but not the specific content of the games before the experiment started.

Subjects were first given instructions for the priming experiment (see details in section 3.1). There were no time constraints. Immediately after the prime, they participated in games that were designed to elicit their individual attitude toward risk, their individual attitude toward loss, their time preferences (i.e., regarding being patient and therefore future oriented or impatient and more interested in short-term gains), and their individual attitude toward trust and trustworthiness, followed by a short questionnaire with survey questions. The instructions for each game were given after the decisions they had made in the previous game were collected.

One of the risk, loss, and time preference games was randomly chosen and played for a monetary prize. The investment game, to elicit trust and trustworthiness, always involved a monetary prize. ${ }^{10}$ This determination of the payments was explained to subjects before the experiment began. At the start of each experiment, each subject was told that they receive 100 tokens as their show-up fee. On average, subjects received an additional 400 tokens for the experiment that took approximately one hour. At the end of the experiment, every token they earned was converted to 1 national Taiwan dollar or 0.1 Chinese yuan. ${ }^{11}$ The exchange rates between tokens and local currencies were scaled for parity, using the hourly wage of a student research assistant as the common metric. To avoid present biases triggered by transaction costs of future payments when eliciting time preferences, all payments (including the participation fee) were transferred by wire to subjects' bank accounts. ${ }^{12}$

\subsection{Priming Experiment}

\footnotetext{
${ }^{10}$ Investment game is a 2-person game. Each subject is paired with an anonymous subject. The fact that the investment game may ultimately not be selected for a payout (by their partner) could subtly affect subjects' decisions during the game. For this reason, we decided to always pay out on the investment game.

${ }^{11}$ The exchange rate of 1 national Taiwan dollar to 1 Chinese yuan was 4.8 to 1 at the time of the experiments. ${ }^{12}$ Based on our observation, having a bank account was common in our sample pools. In fact, NTU requires its students to receive most university payments and reimbursements via direct deposit.
} 
We employed a between-subjects design where each subject participated in the experiment once only. Half of the subjects in each school were randomly assigned to the Confucius prime (treatment group) and half assigned to the neutral prime (control group). For those in the treatment group, we selected six pieces of classic texts from the Analects of Confucius and Mencius and inserted one incorrect character in each of the quotes; we refer to these as word problems hereafter. The incorrect characters were either phonetically similar or had a similar meaning. Subjects were asked to identify the wrong characters and to rewrite the entire sentence with the corrected characters on the answer sheet. If they could not identify the mistake, they were told to simply copy the entire sentence anyway. For the control group, we selected six sentences from contemporary Chinese writing that were unrelated to Confucianism and asked subjects to perform the same task. In fact, we were not interested in whether the subjects could identify the incorrect character; rather, what was important was that our priming worked by having them read and then rewrite the text, therefore manipulating the salience of Confucianism. ${ }^{13}$

For example, this is one of the statements for the treatment group (translation: "Confucius said: Learning without thought is labor lost; thought without learning is perilous.”):

(wrong) 子曰: 学而不思则罔, 思而不学则迷

(correct) 子曰: 学而不思则罔, 思而不学则殆

This is one of the statements for the control group (translation: "I want to write about those family stories told from the generations to generations"):

(wrong) 我要寫的是那些傳誦不已的親情故事

(correct) 我要寫的是那些傳頌不已的親情故事

We carefully selected texts that were unrelated to any of the preferences we elicited about risk, loss, time preference, and trust and trustworthiness. (The full list of the texts we chose is presented with translation in the web appendix.) For example, we avoided using as a prime the Confucius saying: "If a

\footnotetext{
${ }^{13}$ To our knowledge, this is the first paper that primes Confucianism. We created and tested this priming instrument.
} 
man takes no thought about what is distant, he will find sorrow near at hand." This saying could have a direct impact on time preference even without evoking one's attitude about Confucianism. Had we used this saying as a prime, it would have been difficult to disentangle the effect of Confucianism with the direct effect of this particular reminder. We also conducted pilot tests to ensure that the tasks of identifying wrong characters were of similar difficulty for the treatment and control groups.

For comparison reasons, we asked both the treatment and control groups to complete each other's word problem at the end of the entire experiment. In addition, subjects' performance on these word problems provided an objective assessment of their knowledge of Confucianism. ${ }^{14}$

\subsection{Incentivized Lottery Choice Task I: Risk Aversion}

In this experiment, modeled after Holt and Laury (2002), each subject was asked to make decisions on a series of nine binary-choice questions between a safe option and a risky option. The choices and the difference in expected payoff between risky and safe options are presented in Table 1. Subjects who are more risk averse should choose safer options than those who are less risk averse. Subjects who are risk neutral should choose the safe options (choice A) for questions 1 to 4 (Q1-Q4) and risky options (choice B) for questions 5 to 9 (Q5-Q9). Subjects' degree of risk aversion was based on the number of safe options they chose. Following Holt and Laury's methodology, we assume the following utility functional form:

$$
U(x)=\frac{x^{1-\sigma}}{1-\sigma}
$$

Subjects' choices allowed us to estimate their coefficient of relative risk aversion, $\sigma$.

\subsection{Incentivized Lottery Choice Task II: Loss Aversion}

\footnotetext{
${ }^{14}$ In the exit survey, we asked subjects questions about their upbringing background. We found that subjects who had a more traditional or conservative upbringing performed better on these word problem when controlling for basic demographic characteristics, such as gender, undergraduate major, and parental education.
} 
In order to measure subjects' attitude toward loss, we asked them to decide between binary choices that involve the possibility of losing money in this game. The choices and the differences in expected payoff are presented in Table $2 .{ }^{15}$ For each question, both choice A and choice B have a 50/50 chance of winning or losing money. The amount of possible loss is always lower in choice A (lose 35 tokens) than choice B (ranges from losing 40 to 65 tokens). In Q1, the expected payoff of choice A is better than the expected payoff of B. As one move down the series, choice B (with a higher expected payoff) becomes increasingly more appealing than Choice A. A subject who is risk neutral and not loss averse would choose choice A from Q1 to Q3, would be indifferent between choices A and B in Q4, and would choose choice B from Q5 to Q7. Someone who is loss averse and risk neutral would not be indifferent between choices A and B in Q4 since choice B incurs larger losses than choice A. Ceteris paribus, the more loss-averse person would choose choice A (a low-loss option) more often than a less loss-averse individual before switching to choice B (a high-loss option). This experimental protocol, presented in Table 3, is modeled after Tanaka, Camerer and Nguyen (2010) and Liu (2013). We follow their estimation methodology assuming that the utility functional form is

$$
U(x)=\frac{x^{1-\sigma}}{1-\sigma} \text { if } x \geq 0 \text { and } U(x)=-\lambda * \frac{(-x)^{1-\sigma}}{1-\sigma} \text { if } x<0
$$

Subjects' choices from the risk aversion game and this one allow us to jointly estimate coefficients of relative risk aversion $\sigma$ and loss aversion $\lambda$. The standard expected utility is nested in equation 2 ; if we fail to reject the null hypothesis that $\lambda=1$, there is no evidence of loss aversion.

\subsection{Convex Time Budget Method: Time Preferences}

We adapted Andreoni and Sprenger's (2012) convex time budget (CTB) method to elicit time preferences. Subjects were given 300 experimental tokens to allocate between receiving some tokens at time $t$ and $t+h$, with varying interest rates $r$ over these $h$ periods. Allocating $x$ tokens to time $t$ and

\footnotetext{
${ }^{15}$ To prevent the possibility of subjects paying out of pocket, the participation money for the participants was more than the maximum loss possible in the game.
} 
$(300-x)$ to time $t+h$ would mean that the subject receives $x$ tokens at time $t$ and receives $(300-x) *$

$(1+r)$ at time $t+h \cdot{ }^{16}$ Specifically in the experiment, we asked subjects to make 10 decisions (see Table

4). We set the values of $t$ to be today or 6 weeks later, $h$ equals 4 weeks, and the interest rates, $r$, range between $0.5 \%$ and $2.5 \% .{ }^{17}$ Thus, for a given interest rate, more impatient subjects would allocate more tokens to the earlier payment date (today in games 1 to 5 and 6 weeks in games 6 to 10) than more patient individuals. By varying the earlier payment between today and 6 weeks later, with some assumptions of the utility function form, these choices allow us to estimate the coefficients of exponential discounting and present bias. ${ }^{18}$

We needed to ensure that receiving payments today would be as costly as receiving payments a month later. Otherwise subjects might choose to receive payment today to reduce the possible transaction cost regardless of their discount factor. We announced at the beginning of all experimental sessions that there would be no cash payments to subjects at the end of the experiment; rather, all payments would be transferred to the subjects' bank account. Another concern with elicitation of time preference is that subjects needed to trust that they would actually receive the later payments due them from the experimenters. To gain subjects' trust, we followed the protocol similar to that of Andreoni and Sprenger (2012): all subjects were given the business card of the professors who were in charge of the experiment.

\subsection{Investment Game: Trust and Trustworthiness}

\footnotetext{
${ }^{16}$ We chose the CTB experimental method for several reasons. First, unlike most of the existing literature, such as Andersen et al. (2008) and Tanaka, Camerer and Nguyen (2010), which offer a set of binary choices between $X$ at time $t$ and $Y$ at time $(t+h)$, CTB gives subjects more flexibility and offers a continuum of choices. Second, other than Andersen et al. (2008) and Andreoni and Sprenger (2012), much of literature assumes a linear utility function when estimating time preference parameters. Not incorporating a risk preference measure would cause an upward bias in the estimation of discount rates.

${ }^{17}$ The original CTB experiment protocol also varies the duration of the postponement $h$, which gives authors a more precise estimate of the parameters. By eliminating the variation in $h$, our version of the experiment is shorter than the original CTB due to worries about the strength of the priming effect. The $0.5-2.5 \%$ is the interest rate that occurred after 4 weeks. The annualized interest rates would range between $6 \%$ and $30 \%$. This range of interest rates is based on estimates from Andreoni and Sprenger (2012).

${ }^{18}$ The CTB methodology has also been adapted by Giné, Goldberg, Silverman, and Yang (2012) and Carvalho, Prina, and Sydnor (2013) in Malawi and in Nepal, respectively.
} 
To measure individuals' interpersonal trust and trustworthiness, we modeled our game after Berg, Dickhaut, and McCabe (1995). Each subject was randomly assigned the role of being an investor or a trustee. The investors were given 150 tokens and were paired with a subject who was a trustee, but they were not told who that person was. Investors had seven choices (between 0 and 150 in increments of 25 tokens) of how much to send to their trustee. We tripled the amount the investors decided to send to the trustee in each of six possible scenarios. The share of tokens that the investor gave out served as a proxy for interpersonal trust. Those who were more trusting would invest a higher share of the 150 tokens. The share of tokens returned by a trustee to the investor was a proxy for the trustworthiness of the trustee, where a higher share of tokens being returned indicated the trustee was more trustworthy.

\subsection{Survey}

The survey collected basic information on the participants, including age, gender, major, parental education, and graduate student status; a set of questions asking about their upbringing, which sought to determine how much emphasis their parents had placed on observing Chinese traditions; and a set of questions about their subjective views (e.g., whether they agreed that it is unfortunate to have a daughter and no son). Having these answers to the subjective questions allowed us to construct a proxy for their conservatism that we used in the later analysis.

\subsection{Data and Sample Selection}

Table 4 presents the summary statistics of subject characteristics by university. The last column in the table shows $p$-values on a test of equality of means between PKU and NTU. Among the recruited students, PKU students were more likely to be in graduate studies than the students at NTU. Their parents were also slightly less educated than the parents of NTU students. There are no statistical differences in gender, or in the students' subjective evaluation of their parents' emphasis on a traditional upbringing.

Table 5 performs a randomization check within each school. In neither school are there statistically significant differences between treatment and control groups in all reported background 
characteristics. Given that the randomization between control and treatment groups was successful, in later analysis we can conclude that any detected difference between treatment and control groups is attributed to the reactions to the Confucius prime.

\section{Empirical Analysis}

\subsection{Descriptive Findings}

We first examined the differences between the treatment and control group across each of the games. Figure 1 presents the cumulative distribution over the number of safe choices by treatment status for the risk aversion game. It shows that the distribution of lottery choices for the treatment group is to the left relative to the distribution of the control group, that is, the treatment group chose fewer safe lotteries compared to the control group. Therefore, the treatment group was more risk loving than the control group.

Figure 2 presents the distribution over the number of choice A (low-loss options) by the treatment and control groups in the loss aversion games. Similar to Figure 1, the distribution of the treatment group is also to the left of the distribution of the control group: these groups tended to choose fewer low-loss option, indicating that it was less loss averse than the control group.

In the investment game, investors were asked to invest $0,25,50,75,100,125$, or 150 tokens with an anonymous trustee. Figure 3 presents the distribution over investment choices by treatment and control group. Here, an interesting pattern emerges: the treatment group was more likely to have extreme choices than the control group. A significant higher proportion of the control group invested half of the 150 tokens with the trustee than did those in the treatment group. The treatment group was more likely than the control group likely to invest either 0 or 150 tokens with the trustee. This suggests that after receiving the Confucius prime, subjects become more extreme in their interpersonal trust than subjects who were not treated. 
In this same investment game, trustees would receive $0,75,150,225,300,375$, or 450 tokens. We asked trustees how many of the tokens they would return to the investors for each of the six scenarios (there is no token to be returned if they receive zero). Figure 4 presents the mean share of tokens that trustees returned for each of the scenarios by treatment status. The first noteworthy point is that the more tokens the trustees received, the more they would reciprocate and return a higher share of tokens. The treatment group returned a higher proportion of the tokens to the investors than the control group did regardless how much they received. In other words, the treatment group was more trustworthy than the control group..$^{19}$

Figure 5 shows the choices in the CTB task by treatment status for each of the games. The left panel presents the decisions for the allocation of tokens between receiving it today versus in 4 weeks (games 1 to 5 in Table 3), and the right panel presents the choices made between receiving the tokens in 6 weeks versus 10 weeks (games 6 to 10 in Table 3). Each bar indicates the mean proportion of the tokens allocated to the earlier payment date. The lower the bar is, the more patient the subjects were. There are a few noteworthy points here. First, when interest rates increased, the share of tokens allocated to the earlier date decreased. Second, there seems to be some evidence of present bias to allocating more tokens to an earlier payment for any given interest rate in the left panel than the right panel. However, for the purpose of the comparison across treatment and control groups, the difference is negligible.

\subsection{The Effect of Confucius Prime on Risk Preferences, Trust/Trustworthiness, and Time Preferences}

In this section, we pursued regression analysis in examining the differences in priming effect and report the result in Table 6. First, we compared the responses of the treatment and control groups for their choices in the incentivized lottery tasks. In these regressions, both the direct measure of risk or loss aversion from the experiments (the number of safe options and number of low-loss options) and the

\footnotetext{
${ }^{19}$ Interestingly, the mean proportion of tokens returned (20\%-30\%) in both the treatment and control groups were lower than other trust experiments done with Chinese subjects (Buchan, Johnson, \& Croson, 2006, reported 34\%).
} 
imputed measures of risk or loss aversion coefficients $(\sigma, \lambda$ from equation 2$)$ were the dependent variables. These regressions controlled for a subject's gender, age, whether he or she was a graduate student, his or her father's and mother's education levels, a dummy indicating whether the major was science- or engineering-related, and a dummy indicating that he or she was a PKU student. ${ }^{20}$ Standard errors are clustered at the session level. The regression results and the mean and standard deviation of each of the dependent variables are presented in Table 6 . The coefficients of relative risk aversion have a mean of 0.45 and are similar to other experiments using different experimental protocols in China (Liu, 2013; Frijters, Kong, \& Liu, 2013). We found that the treatment group was less risk averse than the control group at a 5\% level in both the direct and imputed measures of risk aversion. The size of the treatment effect is considerable: one-fifth of a standard deviation. ${ }^{21}$ The treatment group also behaved in a less lossaverse way than the control group, although the coefficients are not statistically different from 0 . Based on our hypothesis in section 2, it is possible that the salience of Confucianism caused subjects to react negatively to Confucian values. We later found that this result was driven by the reaction of PKU students who were behaving in opposition to Confucian values.

Next, we examined interpersonal trust and trustworthiness. Given our finding that the treatment group had more extreme choices than the control group (from Figure 3), it is not surprising that the average treatment effect of the Confucius prime on trust was not statistically different from 0 . In terms of trustworthiness, subjects returned almost 4.57 percentage points more tokens to the investor, a nearly $20 \%$ increase from the baseline. This suggests that the treatment group behaved in a more trustworthy way compared to the control group, in accordance with our prediction.

To examine the impact of treatment on time preference, we had two sets of measures: the share of tokens allocated to the earlier payment (the direct measure) and structurally estimated parameters of discount factors. For the direct measure, each subject was asked to make decisions between receiving

\footnotetext{
${ }^{20}$ Results are robust when these individual characteristics are excluded. This table is available in the Web Appendix on the authors' website, www.uh.edu/ emliu.

${ }^{21}$ To compare the magnitude to other covariates, the treatment effect is larger than coefficients on being female.
} 
payment today or 4 weeks later with varying interest rates (games 1 to 5 in Table 3) and another set of decisions between receiving payments in 6 weeks or 10 weeks later (games 6 to 10 in Table 3). The following equation is estimated for games 1 to 5 and games 6 to 10 separately:

$$
\text { Share Tokens Sooner Payment } \text { Ig }_{\text {Preat }}+r_{g}+X_{i}
$$

where $i$ is indexed for subject, $g$ is an index for game, and $r$ is the corresponding interest rate for game $g$. The dependent variable is the share of tokens allocated to an earlier payment. $X_{i}$ includes the same set of control variables as in other columns of Table 6. However, standard errors are clustered at the individual level. The regression results for the allocation choices for today versus 4 weeks is presented in column 7 , and allocation choices for 6 weeks versus 10 weeks are presented in column 8 of Table 6 . The intertemporal choices between 6 versus 10 weeks capture the discount factor, while the intertemporal choice between today versus 4 weeks encapsulate the present bias and discount factor. As shown here, the direct measures of the effect of the Confucius prime on time preference in a reduced form are not statistically different from 0 .

However, such a simple comparison would ignore the role of concavity in the utility function. For example, two individuals with the same allocation of tokens for an earlier payment in games 1 to 10 could still have different estimated time preference parameters if their risk aversion parameters differed. In particular, following Laibson (1997) and Andreoni and Sprenger (2012), suppose the utility function forms from different periods are time separable and can be expressed as

$$
\begin{aligned}
& U\left(x_{t}, x_{t+k}\right)=x_{t}^{(1-\sigma)}+\beta \delta^{k} x_{t+k}^{(1-\sigma)} \text { if } t=0 \\
& U\left(x_{t}, x_{t+k}\right)=x_{t}^{(1-\sigma)}+\delta^{k} x_{t+k}^{(1-\sigma)} \text { if } t>0
\end{aligned}
$$

In this proposed utility function, $\delta$ is the exponential discount factor and $\beta$ is the present bias. ${ }^{22}$ If $\beta=1$, there is no evidence of present bias; if $\beta<1$, present bias exists. A higher $\delta$ would indicate that a subject is more patient and better able to delay gratification.

\footnotetext{
${ }^{22}$ Anderson et al. (2008) suggest that ignoring the concavity would result in upward bias estimates of discount rates.
} 
As we have shown in Table 6, columns 1 and 2, the concavity of utility function, $\sigma$, differs between treatment and control groups, so it is important to incorporate risk aversion coefficient in our estimation of the time preference parameters by treatment status. Using the estimated risk preference parameters based on subjects' response from the Holt and Laury game and following Andreoni et al.'s (2013) interval censored regression estimation method, we impute the present bias $(\beta)$ and exponential discounting factors $(\delta)$. These parameters are stratified by treatment status and shown in Table $7 .{ }^{23} \beta$ is statistically different from 1 for both treatment and control groups, so we cannot reject the existence of present bias. Interestingly, the treatment group had less present bias but a lower discount factor (the subjects were less patient), which is surprising. In the next section, we find that the reduction in present bias was being driven by the NTU subjects, and the surprising finding of subjects becoming more impatient was being driven by the PKU students, who were reacting negatively to Confucius teaching.

\subsection{Experimental Results by School}

In this section, we examine whether the Confucius priming effect was different between the groups from the two institutions in this study, and we investigate whether the puzzling finding from the previous section is being driven by the negative reaction of PKU students. Our regression specification is

$$
Y_{i}=\gamma_{0} \text { treat }_{i}+\gamma_{1}\left(\text { treat }_{i} * N T U_{i}\right)+\gamma_{2} N T U_{i}+X_{i},
$$

where $i$ indexed for subject $i$, NTU is a dummy indicating whether the subject was an NTU student; $X_{i}$ includes a subject's gender, age, graduate student status, whether major is science and engineering related, and father's as well as mother's education level; treat equals 1 if a subject was in the Confucius-prime group; $\gamma_{0}$ captures the treatment effect on PKU students; and $\gamma_{1}$ is the difference between the treatment

\footnotetext{
${ }^{23}$ Andreoni et al. (2013) propose several different methods of estimating parameters in CTB, including nonlinear least squares and two-limit tobit (censored) maximum likelihood regressions. As they suggest, tobit is a better method when there are corner solutions. In our experiments, we have a considerable number of choices, and for the purpose of our analysis, we do not need individual estimates since we only need to compare the mean across the treatment and control groups. Thus we opted for the censored regression method. In our estimation, we also used the weekly expenditure of 1539 TWD (for PKU students) and 1746 TWD (for NTU students). These expenditures are based on the exit survey.
} 
effect on NTU students and on PKU students. The treatment effect on NTU students would be equal to $\left(\gamma_{0}+\gamma_{1}\right)$. The dependent varible $Y_{i}$ is the same as those in Table 6 . Table 8 shows the coefficients $\left(\gamma_{0}, \gamma_{1}, \gamma_{2}\right)$ and the $p$-values from the $F$-test $\left(\gamma_{0}+\gamma_{1}=0\right)$.

In section 4.2, we saw that being primed on Confucianism caused subjects to behave in a more risk-loving and less loss-averse manner. From columns 1 to 3 of Table 8, it is evident that the negative treatment effect on risk preference and loss aversion was mostly driven by the reactions of the PKU students. The $F$-test results reported in columns 1 to 3 suggest that the priming effects on NTU students were not statistically different from 0 at a $10 \%$ level. Moreover, there was no priming effect on trust for students from either school. Although there is also no significant treatment effect on trustworthiness in each school if separately estimated, the sign of the estimates suggests that the signficantly positive effect of Confucius primes on trustworthiness, reported in the pool regressions of Table 6 , stemmed mainly from the positive reactions of NTU students. Columns 7 and 8, which show the share of tokens invested to the earlier payment, reveal little change in these direct measures of time preferences. ${ }^{24}$

Table 9 presents the structural estimates of present bias and the discount factor from equation 3 stratified by school and treatment status. The treatment groups at NTU (column 4) exhibited less present bias, but those at PKU (column 3) show no statistically significant differences. However, the surprising results from Table 7 that those receiving the Confucius prime became less patient (lower discounting factor) is driven mainly by the changes in PKU students (see Column 1).

In this section, we have presented some evidence that PKU students reacted against the commonly understood Confucian values when they were primed with Confucian teachings, but NTU students reacted in a way that is either consistent with or not affected by the Confucian values. That the

\footnotetext{
${ }^{24}$ As a robustness check, we also split the sample and estimate the treatment effect for the two schools separately. One reason to do this is that the control variables may have different effects on the dependent variables for the Chinese and the Taiwanese students. The results are consistent with the findings in Table 8. However, due to the small sample and a lack of degree of freedom, the standard errors are larger than those in Table 8. This table is available in the Web appendix on the corresponding author's website, www.uh.edu/ emliu.
} 
same primes evoked different feelings in students from the two schools is an interesting finding. ${ }^{25}$ An explanation for these differences may be that the priming instrument we developed was not priming Confucianism but instead evoked other feelings of the PKU students, the reason for this opposite reaction. We investigate this possibility in the next section.

\subsection{Validation Check}

We conducted a few extra surveys at both universities to validate the efficacy of our priming instrument. The surveys, distributed in several economic undergraduate classes to 389 students (none of whom participated in the experiment) in both schools, took about 5 to 10 minutes and the students were not paid. As with our full experiments, subjects were randomly assigned to receive either the Confucius prime or a neutral prime. Immediately after the prime, they were asked to complete a short questionnaire asking about their evaluation of Confucianism and some of their individual characteristics. Two of the questions allowed us to conduct a validation check: "Among the following belief systems (Rationalism, Confucianism, Eastern Religion (Buddhism, Taoism), Western Religion (Catholicism, Christianity, etc), please rank them based on their values from most agree (1) to least agree (4)," and, "On a scale of 1 to10, how much do you agree with each of the following belief systems ( 1 being least agree and 10 being most agree)?" Because these questions were answered immediately after the priming questions, the priming effect, if any, should be clear.

The regression results using these answers are reported in Table 10. In column 1, the dependent variable is the ranking of Confucianism ( 1 being the best, 4 being the worst), and ordered probit estimation method is used. Column 2, the dependent variable, shows how much the students agreed with Confucianism. ${ }^{26}$ In column 3, we created a dummy indicating whether Confucianism was ranked as the most important. The results suggest that the PKU students ranked Confucianism lower and disagreed

${ }^{25}$ Psychologists Wheeler and Berger (2007) suggest that the same priming instrument can have different effects on the subsequent choices of different groups of people.

${ }^{26}$ Each person reported the values for all four belief systems. Some people tended to agree and put down a higher value for all, while others tended to disagree with everything and had lower values for all systems. Thus, the dependent variable is their rating on Confucian value minus their individual mean of evaluation of all four systems. 
more with Confucian values after they received Confucian prime. For NTU students, the Confucius prime improved the ranking of Confucianism and increased how much NTU students agreed with Confucian values than the control group did. Combining the results here with those in the previous section reinforces the idea that PKU students reacted to the Confucius prime differently from the NTU students.

\subsection{Discussion}

While we cannot clearly identify the reasons behind the observed differences in reaction to the Confucianism priming in the two schools, there are a few possible explanations. First, the differences in the sample characteristics may play a role. For instance, Table 4 suggests that the PKU students are slightly older, more likely to be in science- and engineering-related majors, and more likely to be graduate students than NTU students. The parents of PKU students are also less likely to hold a bachelor's degree. However, unreported regressions show that the estimated priming effects in almost all dimensions are not affected by these variables (i.e., students' majors, graduate degree, etc.). ${ }^{27}$ Therefore the school differences in the priming effect are not caused by the differences in these characteristics.

Second, Table 10 shows that Taiwanese students exposed to the neutral prime hold significantly less favorable attitudes toward Confucianism than their Chinese peers. It could be that those who started from a lower identification with Confucianism can demonstrate a larger positive reaction to the priming. However, this line of reasoning cannot explain why PKU students' high level of identification with Confucianism in the neutral treatment is associated with a negative reaction to the Confucianism priming. In a regression not reported here, we investigated whether the treatment effects can differ based on students' subjective view of traditionalism (based on their answers in the exit survey), but found no statistically significant evidence.

Third, there were historical differences in the experiences with Confucianism in these two regions. As we have suggested earlier, the Cultural Revolution in China has devastated many Confucian values for

\footnotetext{
${ }^{27}$ The only significant effect is that if the parents' education levels are higher, then subjects tend to demonstrate more positive treatment effects on the degree of trustworthiness.
} 
a decade, which may have long-lasting effects even today, while in Taiwan Confucianism was relatively well preserved.

As with most laboratory experiments, our studies have certain limitations. First, our subjects are students in top universities in China and Taiwan. Having university students as subjects often raises the question of the external validity of experiments. However, this problem may be less severe given that the key motivation of our study is to understand how Confucian philosophy shapes Chinese society. For more than a thousand years, Confucianism had remained influential in Chinese society because of its key role in imperial civil service examination system (Mayer and Schmidt, 2004). Memorization of Confucian texts had been a necessary preparation for examinations (Elman, 1991), and Confucian morals have been inculcated in intellectuals (Brokaw, 1991). These intellectuals possessed political power and shaped the norms and the thinking of the society. The rest of society was influenced by the Confucian teachings indirectly. Similarly, today, Confucian texts are taught in middle schools and high schools in Taiwan and China, and students are often tested on Confucian texts during college entrance examinations. Hence, university students who are well-versed in Confucian sayings are in fact the subjects we were most interested in. They are influenced by Confucianism directly through active learning and reading texts, unlike the rest who are only indirectly influenced through societal norms. We suspect that those who are uneducated (in Confucian texts) may not have as much reaction to our priming task at all.

Second, our validation tests were carried out on a more special group of students who had economics major, and so the validation results may not directly apply to students in other majors. In unreported regressions, we find that the priming effects are not affected by students' majors, which to some extent alleviates the problem.

\section{Conclusion}

We investigated how Chinese and Taiwanese subjects reacted to Confucius primes and whether there were differences of reaction between the two groups. Our findings suggest that subjects became more risk loving, more impatient, less present-biased and more trustworthy when they were exposed to a 
Confucius prime. However, this simple characterization of the impact of Confucianism is misleading since we found differences in priming effects depending on whether they are from China or from Taiwan.

Chinese subjects who were primed for Confucianism became more risk loving, less loss averse and more impatient than the control group, behaviors not in accord with Confucian values. Taiwanese subjects who were primed for Confucianism demonstrated less present bias than the control group, and was also the main driver force for the more trustworthy treatment effect, in accordance with Confucian values. We performed validation checks of our priming instruments by asking subjects to rank four different belief systems (Confucianism, rationalism, Eastern religion, and Western religion) and reported on a scale of 1 to 10 on how much they agreed with each of these systems. Chinese subjects who were primed for Confucianism were more likely to rank Confucianism lower and also tended to agree less with Confucian values than the control group did. We did not find this effect on the Taiwan subjects. Our study therefore suggests that Chinese and Taiwanese subjects have different reactions to Confucianism. Different historical events and experiences in the two places are a very likely explanation for these differences.

There has been a revival of interest in Confucianism in China. Unlike the anti-Confucius rhetoric from the 1960s and 1970s, government officials have once again acknowledged Confucius as a great contributor to the glorious Chinese tradition. Professor Yu Dan at Beijing Normal University has a popular TV show on the Analects of Confucius and her book, Reflection on the Analects, became a top seller in 2009. Our study suggests that social norms and social identities may be sticky, but they can also be altered. It is possible that we will see the currently diverging paths between China and Taiwan converging again. 
Figure 1: Cumulative Distribution of Safe Choices in Lottery Game I

By Treatment Status

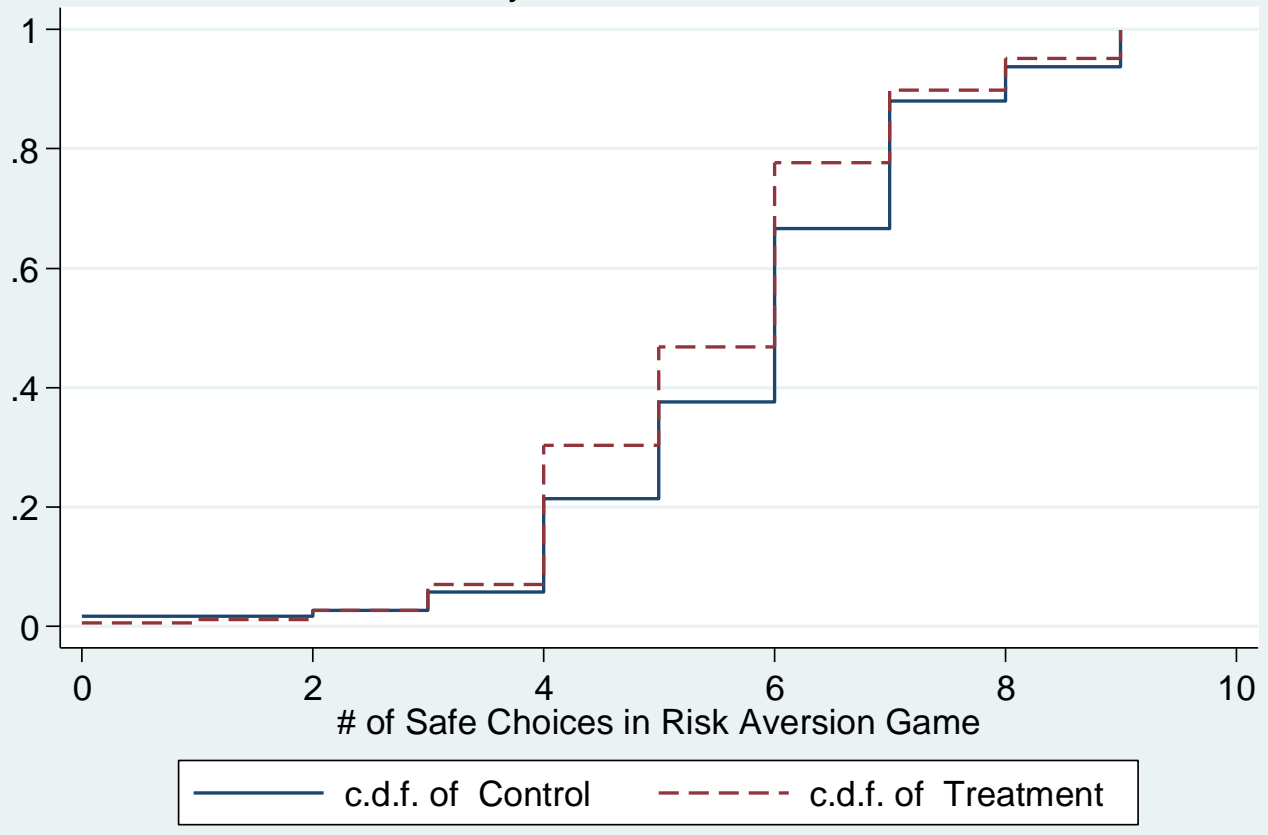

Figure 2: Cumulative Distribution of Low-Loss Choices in Lottery Game II By Treatment Status

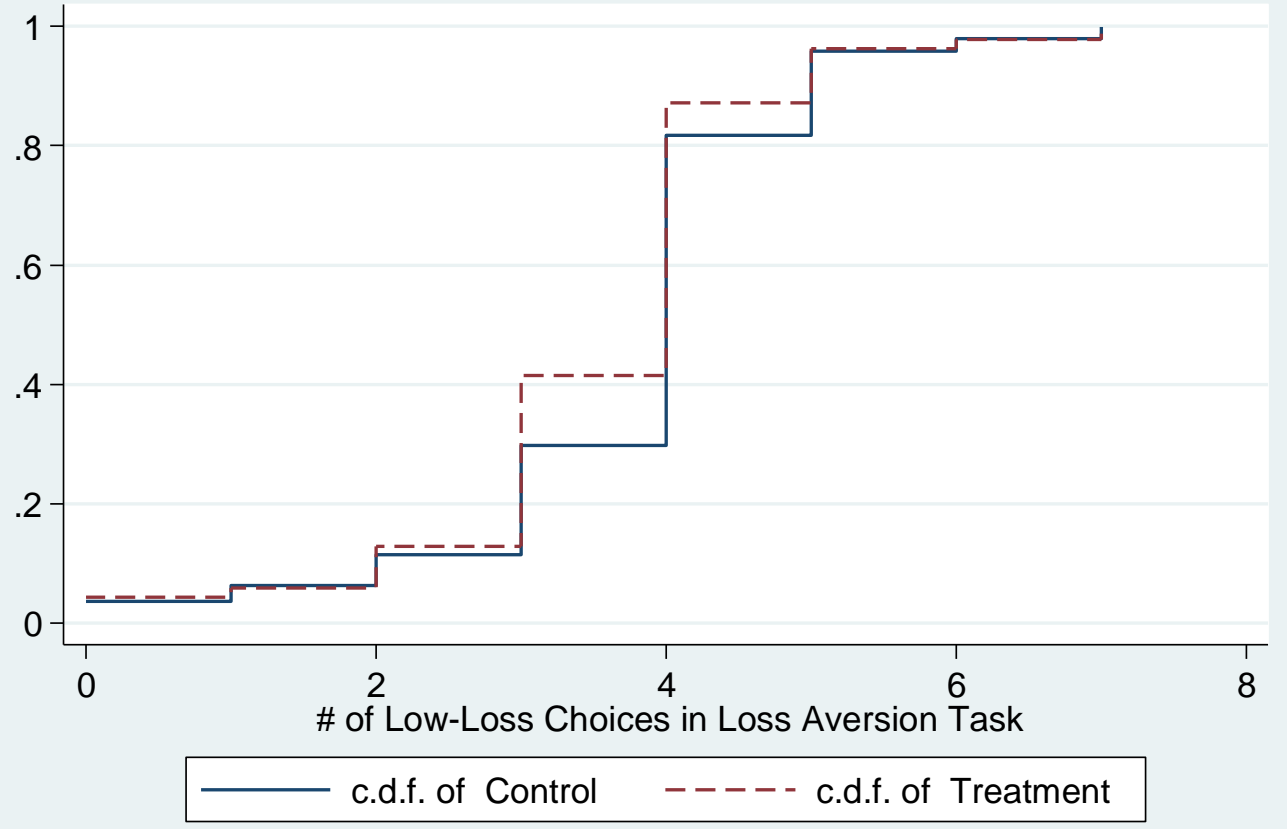


Figure 3: Probability Distribution of Tokens Invested By Tokens Given and Treatment Status

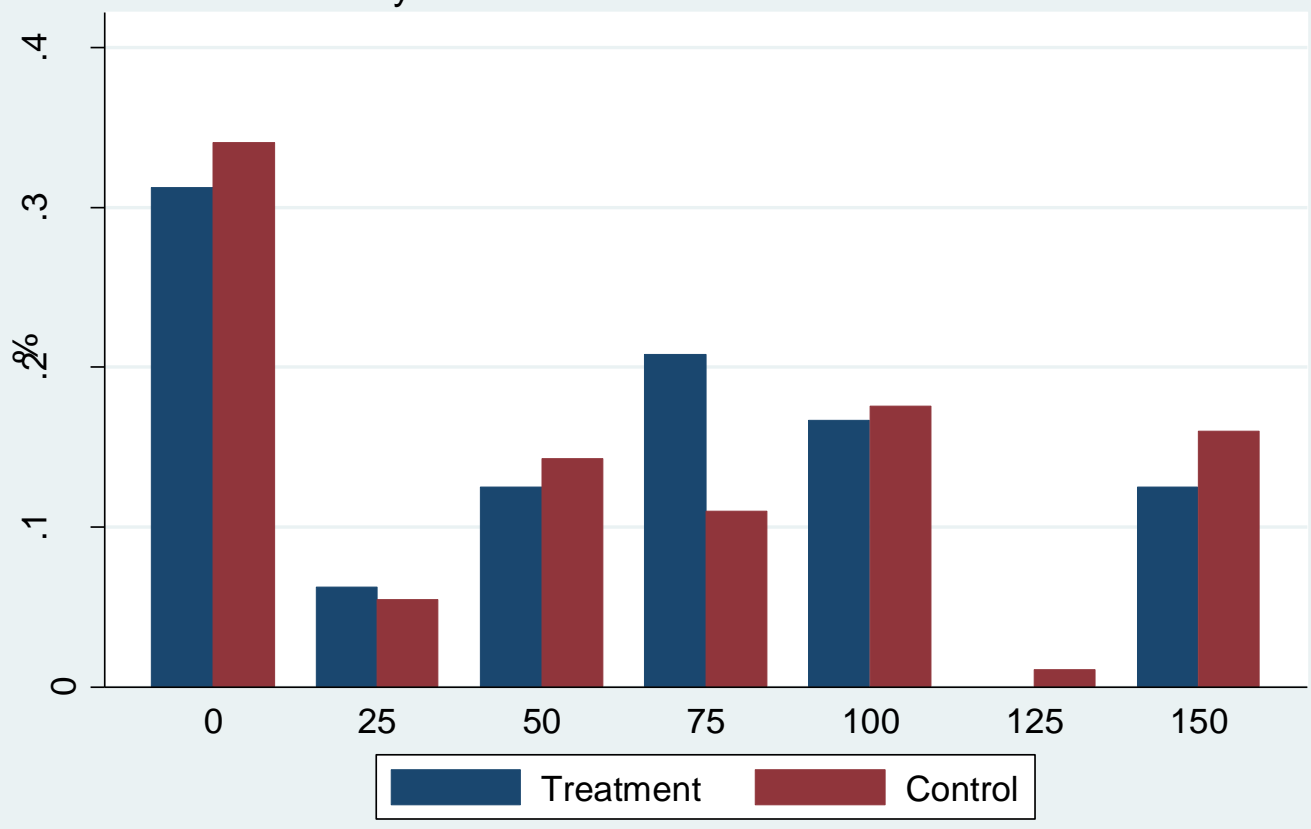

Figure 4: Average Share of Tokens Returned By Token Received and Treatment Status

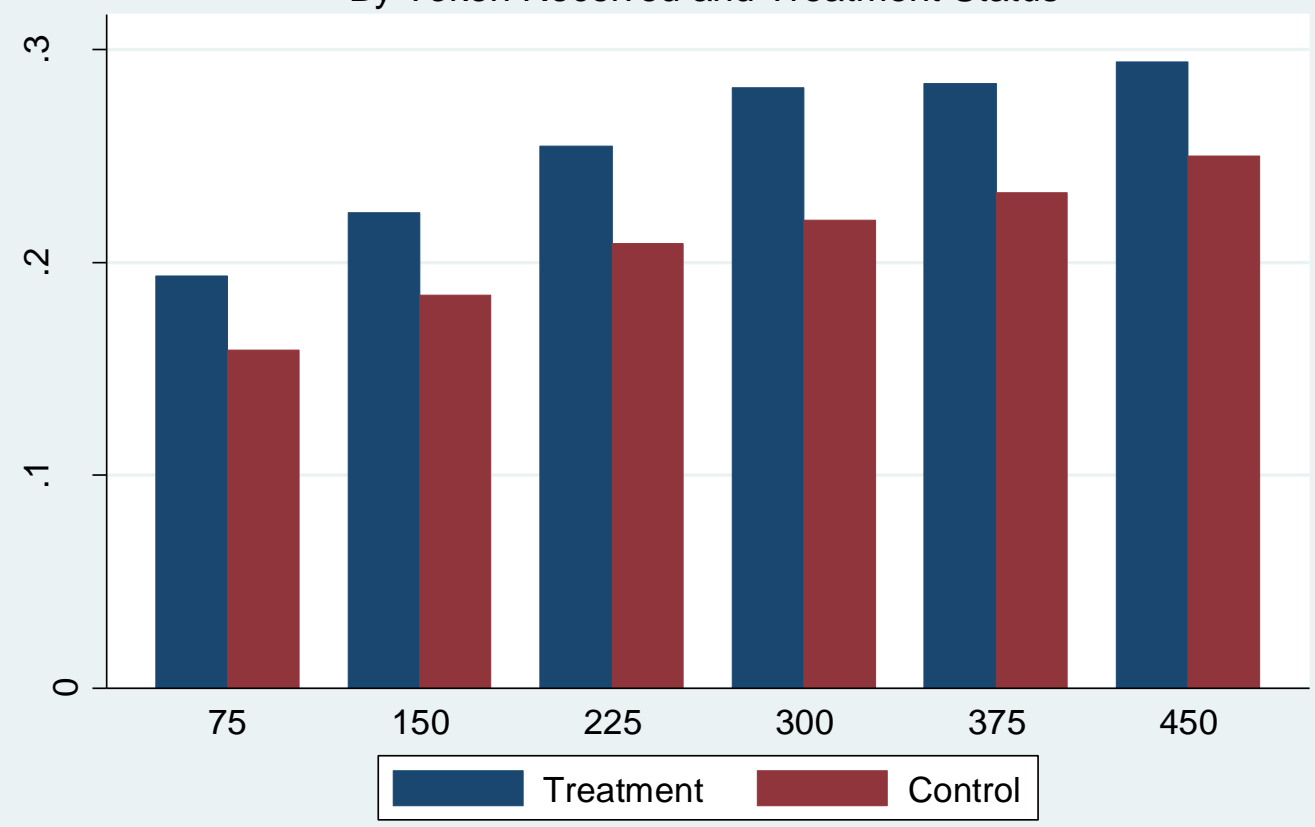


Figure 5: Proportion of Tokens Allocated to Earlier Payment Stratified by Treatment Status and by Interest Rates

Today versus 4 Weeks

$\infty$

ต

ฯ

○
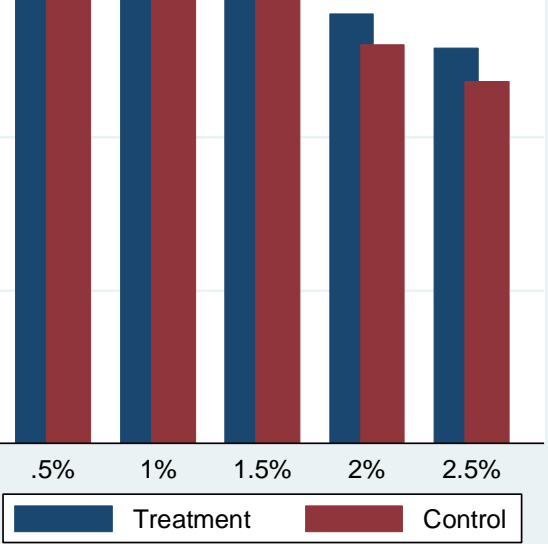

6 weeks versus 10 Weeks $\infty$.

$\circ$

$\infty$

ก

$\circ$

$.5 \%$
6 weeks versus 10 Weeks

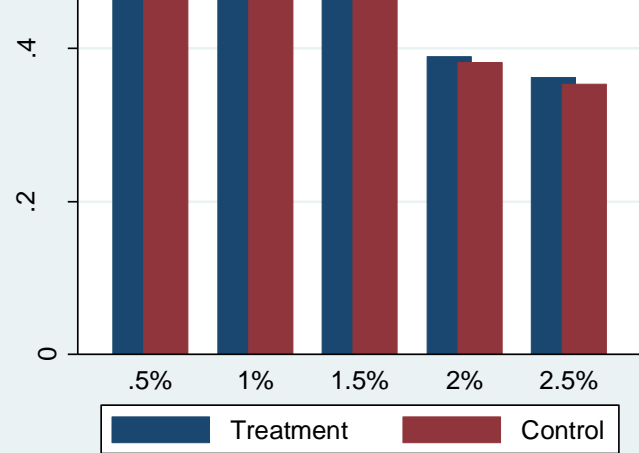


Table 1: Risk Aversion Experiment

\begin{tabular}{|c|c|c|c|}
\hline & Choice A (Safe Option) & Choice B (Risky Option) & $\begin{array}{l}\text { Differences in Expected } \\
\text { Payoff (A-B) }\end{array}$ \\
\hline 1 & $\begin{array}{l}\text { 10\% Probability Winning } 200 \text { tokens } \\
90 \% \text { Probability Winning } 160 \text { tokens }\end{array}$ & $\begin{array}{l}\text { 10\% Probability Winning } 385 \text { tokens } \\
90 \% \text { Probability Winning } 10 \text { tokens }\end{array}$ & 116.5 \\
\hline 2 & $\begin{array}{l}20 \% \text { Probability Winning } 200 \text { tokens } \\
80 \% \text { Probability Winning } 160 \text { tokens }\end{array}$ & $\begin{array}{l}20 \% \text { Probability Winning } 385 \text { tokens } \\
80 \% \text { Probability Winning } 10 \text { tokens }\end{array}$ & 83 \\
\hline 3 & $\begin{array}{l}\text { 30\% Probability Winning } 200 \text { tokens } \\
70 \% \text { Probability Winning } 160 \text { tokens }\end{array}$ & $\begin{array}{l}\text { 30\% Probability Winning } 385 \text { tokens } \\
70 \% \text { Probability Winning } 10 \text { tokens }\end{array}$ & 49.5 \\
\hline 4 & $\begin{array}{l}\text { 40\% Probability Winning } 200 \text { tokens } \\
60 \% \text { Probability Winning } 160 \text { tokens }\end{array}$ & $\begin{array}{l}40 \% \text { Probability Winning } 385 \text { tokens } \\
60 \% \text { Probability Winning } 10 \text { tokens }\end{array}$ & 16 \\
\hline 5 & $\begin{array}{l}50 \% \text { Probability Winning } 200 \text { tokens } \\
50 \% \text { Probability Winning } 160 \text { tokens }\end{array}$ & $\begin{array}{l}\text { 50\% Probability Winning } 385 \text { tokens } \\
50 \% \text { Probability Winning } 10 \text { tokens }\end{array}$ & -17.5 \\
\hline 6 & $\begin{array}{l}60 \% \text { Probability Winning } 200 \text { tokens } \\
40 \% \text { Probability Winning } 160 \text { tokens }\end{array}$ & $\begin{array}{l}60 \% \text { Probability Winning } 385 \text { tokens } \\
40 \% \text { Probability Winning } 10 \text { tokens }\end{array}$ & -51 \\
\hline 7 & $\begin{array}{l}\text { 70\% Probability Winning } 200 \text { tokens } \\
\text { 30\% Probability Winning } 160 \text { tokens }\end{array}$ & $\begin{array}{l}\text { 70\% Probability Winning } 385 \text { tokens } \\
\text { 30\% Probability Winning } 10 \text { tokens }\end{array}$ & -84.5 \\
\hline 8 & $\begin{array}{l}80 \% \text { Probability Winning } 200 \text { tokens } \\
20 \% \text { Probability Winning } 160 \text { tokens }\end{array}$ & $\begin{array}{l}\text { 80\% Probability Winning } 385 \text { tokens } \\
20 \% \text { Probability Winning } 10 \text { tokens }\end{array}$ & -118 \\
\hline 9 & $\begin{array}{l}\text { 90\% Probability Winning } 200 \text { tokens } \\
10 \% \text { Probability Winning } 160 \text { tokens }\end{array}$ & $\begin{array}{l}\text { 90\% Probability Winning } 385 \text { tokens } \\
10 \% \text { Probability Winning } 10 \text { tokens }\end{array}$ & -151.5 \\
\hline
\end{tabular}


Table 2: Eliciation of Loss Aversion

\begin{tabular}{|c|c|c|c|}
\hline & Choice A (Low Loss Option) & "Choice B (High Loss Option) & $\begin{array}{l}\text { Differences in } \\
\text { Expected Payoff (A-B) }\end{array}$ \\
\hline 1 & $\begin{array}{l}50 \% \text { Probability Winning } 60 \text { tokens } \\
50 \% \text { Probability Losing } 35 \text { tokens }\end{array}$ & $\begin{array}{l}50 \% \text { Probability Winning } 75 \text { tokens } \\
50 \% \text { Probability Losing } 65 \text { tokens }\end{array}$ & 7.5 \\
\hline 2 & $\begin{array}{l}50 \% \text { Probability Winning } 55 \text { tokens } \\
50 \% \text { Probability Losing } 35 \text { tokens }\end{array}$ & $\begin{array}{l}50 \% \text { Probability Winning } 75 \text { tokens } \\
50 \% \text { Probability Losing } 65 \text { tokens }\end{array}$ & 5 \\
\hline 3 & $\begin{array}{l}50 \% \text { Probability Winning } 50 \text { tokens } \\
50 \% \text { Probability Losing } 35 \text { tokens }\end{array}$ & $\begin{array}{l}50 \% \text { Probability Winning } 75 \text { tokens } \\
50 \% \text { Probability Losing } 65 \text { tokens }\end{array}$ & 2.5 \\
\hline 4 & $\begin{array}{l}50 \% \text { Probability Winning } 45 \text { tokens } \\
50 \% \text { Probability Losing } 35 \text { tokens }\end{array}$ & $\begin{array}{l}50 \% \text { Probability Winning } 75 \text { tokens } \\
50 \% \text { Probability Losing } 65 \text { tokens }\end{array}$ & 0 \\
\hline 5 & $\begin{array}{l}50 \% \text { Probability Winning } 40 \text { tokens } \\
50 \% \text { Probability Losing } 35 \text { tokens }\end{array}$ & $\begin{array}{l}50 \% \text { Probability Winning } 75 \text { tokens } \\
50 \% \text { Probability Losing } 50 \text { tokens }\end{array}$ & -10 \\
\hline 6 & $\begin{array}{l}50 \% \text { Probability Winning } 40 \text { tokens } \\
50 \% \text { Probability Losing } 35 \text { tokens }\end{array}$ & $\begin{array}{l}50 \% \text { Probability Winning } 75 \text { tokens } \\
50 \% \text { Probability Losing } 45 \text { tokens }\end{array}$ & -12.5 \\
\hline 7 & $\begin{array}{l}50 \% \text { Probability Winning } 35 \text { tokens } \\
50 \% \text { Probability Losing } 35 \text { tokens }\end{array}$ & $\begin{array}{l}50 \% \text { Probability Winning } 75 \text { tokens } \\
50 \% \text { Probability Losing } 40 \text { tokens }\end{array}$ & -17.5 \\
\hline
\end{tabular}

Table 3: Choices for Convex Time Budget Task

\begin{tabular}{llll}
\hline \hline Game & Interest Rate $(\mathrm{r})$ & Sooner Date $(\mathrm{t})$ & Later Date $(\mathrm{t}+\mathrm{h})$ \\
1 & $0.50 \%$ & today & 4 weeks \\
2 & $1 \%$ & today & 4 weeks \\
3 & $1.50 \%$ & today & 4 weeks \\
4 & $2 \%$ & today & 4 weeks \\
5 & $2.50 \%$ & today & 4 weeks \\
6 & $0.50 \%$ & 6 weeks & 10 weeks \\
7 & $1 \%$ & 6 weeks & 10 weeks \\
8 & $1.50 \%$ & 6 weeks & 10 weeks \\
9 & $2 \%$ & 6 weeks & 10 weeks \\
10 & $2.50 \%$ & 6 weeks & 10 weeks \\
\hline \hline
\end{tabular}

Note: Subjects decide how much (of the 300 tokens) to receive earlier rather than later for each of the 10 games. The amount allocated at the later date would earn interest at the corresponding interesting rate. 
Table 4: Subject Characteristics Stratified by Schools

\begin{tabular}{|c|c|c|c|}
\hline & $\begin{array}{l}\text { Peking } \\
\text { University }\end{array}$ & $\begin{array}{l}\text { National } \\
\text { Taiwan } \\
\text { University }\end{array}$ & $\begin{array}{l}\text { P-value of } \\
\text { Hypothesis } \\
\text { Testing }\end{array}$ \\
\hline Female & $\begin{array}{l}0.503 \\
(0.501)\end{array}$ & $\begin{array}{l}0.425 \\
(0.496)\end{array}$ & 0.13 \\
\hline Age & $\begin{array}{l}22.48 \\
(2.485)\end{array}$ & $\begin{array}{l}21.25 \\
(2.259)\end{array}$ & 0.00 \\
\hline Graduate Students & $\begin{array}{l}0.503 \\
(0.501)\end{array}$ & $\begin{array}{l}0.290 \\
(0.455)\end{array}$ & 0.00 \\
\hline Majoring in Science or Engineering Related Fields $(1=\mathrm{Yes} ; 2=\mathrm{No})^{\mathrm{a}}$ & $\begin{array}{l}0.436 \\
(0.497)\end{array}$ & $\begin{array}{l}0.297 \\
(0.458)\end{array}$ & 0.00 \\
\hline Conservative upbringing ( $1=$ certainly not.. $4=$ certainly yes $)$ & $\begin{array}{l}2.785 \\
(0.858)\end{array}$ & $\begin{array}{l}2.737 \\
(0.727)\end{array}$ & 0.52 \\
\hline Father's education level ${ }^{\mathrm{b}}$ & $\begin{array}{l}2.795 \\
(0.091)\end{array}$ & $\begin{array}{l}3.228 \\
(0.092)\end{array}$ & 0.00 \\
\hline Mother's education level ${ }^{\mathrm{b}}$ & $\begin{array}{l}2.443 \\
(0.089)\end{array}$ & $\begin{array}{l}2.892 \\
(0.082)\end{array}$ & 0.00 \\
\hline Observations & 185 & 195 & \\
\hline
\end{tabular}

Note: The means are reported for each question. Standard deviations are reported in parentheses. The last column reports the p-values of the two-way tests of the equality of the means between schools.

a. Graduate students would report their current field of study. We use the standard definition of Science, Technology, Engineering and Mathematics (STEM) fields.

b. 1=below high school;2=high school;3=associate degree;4=bachelor degree;5=graduate degree 
Table 5: Randomization Check

\begin{tabular}{|c|c|c|c|c|c|c|c|}
\hline \multicolumn{8}{|c|}{ Panel A: National Taiwan University } \\
\hline VARIABLES & Female & Age & $\begin{array}{c}\text { Graduate } \\
\text { Student } \\
\end{array}$ & $\begin{array}{c}\text { Father's } \\
\text { Education }\end{array}$ & $\begin{array}{c}\text { Mother's } \\
\text { Education } \\
\end{array}$ & $\begin{array}{c}\text { Conservative } \\
\text { Upbringing }\end{array}$ & STEM Major \\
\hline \multirow[t]{2}{*}{ Confucius Prime } & -0.033 & 0.402 & 0.109 & -0.02 & 0.02 & -0.153 & -0.052 \\
\hline & $(0.058)$ & $(0.814)$ & $(0.139)$ & $(0.195)$ & $(0.175)$ & $(0.120)$ & $(0.083)$ \\
\hline \multirow[t]{2}{*}{ Constant } & $0.441 * * *$ & $21.04 * * *$ & $0.235 * * *$ & $3.238 * * *$ & $2.882 * * *$ & $2.804 * * *$ & $0.324 * * *$ \\
\hline & $(0.0397)$ & $(0.450)$ & $(0.0734)$ & $(0.0863)$ & $(0.114)$ & $(0.0737)$ & $(0.0468)$ \\
\hline Observations & 195 & 195 & 195 & 193 & 194 & 195 & 194 \\
\hline R-squared & 0.001 & 0.008 & 0.014 & 0.000 & 0.000 & 0.011 & 0.003 \\
\hline \multicolumn{8}{|c|}{ Panel B: Peking University } \\
\hline VARIABLES & Female & Age & $\begin{array}{c}\text { Graduate } \\
\text { Student }\end{array}$ & $\begin{array}{c}\text { Father's } \\
\text { Education }\end{array}$ & $\begin{array}{c}\text { Mother's } \\
\text { Education }\end{array}$ & $\begin{array}{c}\text { Conservative } \\
\text { Upbringing }\end{array}$ & STEM Major \\
\hline \multirow[t]{2}{*}{ Confucius Prime } & -0.038 & 0.115 & 0.027 & -0.011 & 0.063 & -0.230 & -0.049 \\
\hline & $(0.059)$ & $(0.467)$ & $(0.115)$ & $(0.232)$ & $(0.167)$ & $(0.130)$ & $(0.041)$ \\
\hline \multirow[t]{2}{*}{ Constant } & $0.522 * * *$ & $22.42 * * *$ & $0.489 * * *$ & $2.800 * * *$ & $2.411 * * *$ & $2.900 * * *$ & $0.460 * * *$ \\
\hline & $(0.0236)$ & $(0.263)$ & $(0.0423)$ & $(0.164)$ & $(0.0714)$ & $(0.0761)$ & $(0.0726)$ \\
\hline Observations & 185 & 185 & 185 & 185 & 185 & 184 & 182 \\
\hline R-squared & 0.001 & 0.001 & 0.001 & 0.000 & 0.001 & 0.018 & 0.002 \\
\hline
\end{tabular}

Note: Confucius Prime is a dummy for subjects receiving Confucian-salient primes. Randomization checks are separated by schoool. Robust standard errors in parentheses. $* * * \mathrm{p}<0.01, * * \mathrm{p}<0.05, * \mathrm{p}<0.1$. Dependent variables are subjects' characteristics. Conservative upbringing is the answer to question "Did your parents emphasize traditional values (such as Confucianism) at home? $1=$ certainly not, .. 4 = certainly yes." We use the standard definition of Science, Technology, Engineering and Mathematics (STEM) fields. 
Table 6: The Priming Effects on Risk Preferences, Trust/Trustworthy and Time Preferences

\begin{tabular}{|c|c|c|c|c|c|c|c|c|}
\hline & (1) & $(2)$ & (3) & (4) & $(5)$ & (6) & (7) & (8) \\
\hline VARIABLES & $\begin{array}{c}\text { Number of } \\
\text { Safe } \\
\text { Choices in } \\
\text { Lottery Task I }\end{array}$ & $\begin{array}{c}\text { Coefficient of } \\
\text { Relative Risk } \\
\text { Aversion }\end{array}$ & $\begin{array}{l}\text { Number of } \\
\text { Low loss } \\
\text { Choices } \\
\text { in Task II }\end{array}$ & $\begin{array}{l}\text { Coefficient of } \\
\text { Loss Aversion }\end{array}$ & $\begin{array}{c}\text { Share of } \\
\text { Tokens } \\
\text { Invested in } \\
\text { Investment } \\
\text { Game }\end{array}$ & $\begin{array}{c}\text { Average Share } \\
\text { of Tokens } \\
\text { Returned in } \\
\text { Investment } \\
\text { Game }\end{array}$ & $\begin{array}{c}\text { Share of } \\
\text { Token Invest } \\
\text { in Today }\end{array}$ & $\begin{array}{c}\text { Share of } \\
\text { Token Invest } \\
\text { in } 6 \mathrm{wks}\end{array}$ \\
\hline Mean(Dep Variable) & 5.65 & 0.45 & 3.64 & 1.54 & 0.40 & 0.23 & 0.61 & 0.47 \\
\hline Standard Dev (Dep Variable) & [1.64] & {$[0.47]$} & [1.25] & [1.38] & {$[0.35]$} & {$[0.19]$} & [0.39] & {$[0.40]$} \\
\hline Confucius Prime & $\begin{array}{c}-0.259 * * \\
(0.115)\end{array}$ & $\begin{array}{c}-0.074 * * \\
(0.033)\end{array}$ & $\begin{array}{l}-0.115 \\
(0.117)\end{array}$ & $\begin{array}{l}-0.052 \\
(0.145)\end{array}$ & $\begin{array}{c}0.016 \\
(0.038)\end{array}$ & $\begin{array}{l}0.049 * \\
(0.023)\end{array}$ & $\begin{array}{c}0.025 \\
(0.040)\end{array}$ & $\begin{array}{c}0.006 \\
(0.042)\end{array}$ \\
\hline Constant & $\begin{array}{c}6.630 * * * \\
(1.123)\end{array}$ & $\begin{array}{c}0.726 * * \\
(0.310)\end{array}$ & $\begin{array}{c}5.130 * * * \\
(0.829)\end{array}$ & $\begin{array}{c}3.199 * * \\
(1.267)\end{array}$ & $\begin{array}{c}0.459 \\
(0.319)\end{array}$ & $\begin{array}{l}-0.017 \\
(0.263)\end{array}$ & $\begin{array}{c}0.738 * * * \\
(0.276)\end{array}$ & $\begin{array}{c}0.288 \\
(0.271)\end{array}$ \\
\hline \multicolumn{9}{|l|}{ Individual Characteristics } \\
\hline Included & Yes & Yes & Yes & Yes & Yes & Yes & Yes & Yes \\
\hline Observations & 373 & 373 & 373 & 373 & 185 & 188 & 1,865 & 1,855 \\
\hline R-squared & 0.039 & 0.037 & 0.061 & 0.044 & 0.020 & 0.044 & 0.098 & 0.069 \\
\hline
\end{tabular}

Note: Standard errors are clustered at the session level. Confucius Prime is a dummy for subjects receiving Confucian-salient primes. Variables indicating the father's and mother's education level, a dummy variable indicating pku student, subject's age, a dummy variable indicating graduate student, a dummy indicating science/engineering related major, an index for conservative upbringing, and a dummy variable for female are included. 
Table 7: Time Preference Parameters By Treatment Status

\begin{tabular}{|c|c|c|}
\hline \multicolumn{3}{|c|}{ (1) } \\
\hline & Delta (Discount Factor) & Beta (Present Bias) \\
\hline \multirow[t]{2}{*}{ Confucius Prime } & 0.9914 & 0.9359 \\
\hline & $(0.0002)$ & $(0.0017)$ \\
\hline \multirow[t]{2}{*}{ Neutral Prime } & 0.9932 & 0.9270 \\
\hline & $(0.0001)$ & $(0.0016)$ \\
\hline $\begin{array}{l}\text { P-Value for F-Test } \\
\text { [Confucius-Prime=Neutral Prime }]\end{array}$ & 0.0000 & 0.0001 \\
\hline \multicolumn{3}{|c|}{$\begin{array}{l}\text { Note: Standard errors are in parentheses. These parameters are estimated using individual risk } \\
\text { aversion (imputed using subjects' choice made in ncentivized lottery choice described in Section } \\
\text { 3.2) and assume the mean weekly expenditure level to be } 1657 \mathrm{NTD} \text {, as calculated based on the } \\
\text { exit survey. Confucius Prime indicate subjects receiving Confucian-salient primes and neutral } \\
\text { prime indicate subjects receiving nuetral primes. Column } 1 \text { reports the estimation of discount } \\
\text { factor and column } 2 \text { reports the estimation for present bias. The p-value of the two-way tests of the } \\
\text { equality between treatment and control groups is reported. }\end{array}$} \\
\hline
\end{tabular}


Table 8: Confucius Priming Effects by Schools

\begin{tabular}{|c|c|c|c|c|c|c|c|c|}
\hline VARIABLES & $\begin{array}{l}\text { Number of } \\
\text { Safe } \\
\text { Choices in } \\
\text { Lottery Task I }\end{array}$ & $\begin{array}{l}\text { Coefficient of } \\
\text { Relative Risk } \\
\text { Aversion }\end{array}$ & $\begin{array}{l}\text { Number of } \\
\text { Low loss } \\
\text { Choices } \\
\text { in Task II }\end{array}$ & $\begin{array}{l}\text { Coefficient of } \\
\text { Loss } \\
\text { Aversion }\end{array}$ & $\begin{array}{c}(5) \\
\text { Share of } \\
\text { Tokens } \\
\text { Invested in } \\
\text { Investment } \\
\text { Game }\end{array}$ & $\begin{array}{c}(6) \\
\text { Average } \\
\text { Share of } \\
\text { Tokens } \\
\text { Returned in } \\
\text { Investment } \\
\text { Game }\end{array}$ & $\begin{array}{c}\text { Share of } \\
\text { Token Invest } \\
\text { in Today }\end{array}$ & $\begin{array}{c}\text { Share of } \\
\text { Token Invest } \\
\text { in } 6 \text { wks }\end{array}$ \\
\hline Mean(Dep Variable) & 5.65 & 0.45 & 3.64 & 1.54 & 0.40 & 0.23 & 0.61 & 0.47 \\
\hline Standard Dev(Dep Variable) & [1.64] & {$[0.47]$} & [1.25] & {$[1.38]$} & {$[0.35]$} & {$[0.19]$} & {$[0.39]$} & {$[0.40]$} \\
\hline Confucius Prime $(\gamma 0)$ & $\begin{array}{l}-0.332 * \\
(0.172)\end{array}$ & $\begin{array}{l}-0.094^{*} \\
(0.050)\end{array}$ & $\begin{array}{l}-0.219^{*} \\
(0.109)\end{array}$ & $\begin{array}{l}-0.258 \\
(0.224)\end{array}$ & $\begin{array}{c}0.039 \\
(0.040)\end{array}$ & $\begin{array}{c}0.033 \\
(0.024)\end{array}$ & $\begin{array}{c}0.035 \\
(0.055)\end{array}$ & $\begin{array}{l}-0.002 \\
(0.062)\end{array}$ \\
\hline Confucius Prime $*$ NTU $(\gamma 1)$ & $\begin{array}{c}0.143 \\
(0.213)\end{array}$ & $\begin{array}{c}0.039 \\
(0.062)\end{array}$ & $\begin{array}{c}0.203 \\
(0.215)\end{array}$ & $\begin{array}{c}0.401 \\
(0.302)\end{array}$ & $\begin{array}{l}-0.045 \\
(0.075)\end{array}$ & $\begin{array}{c}0.031 \\
(0.050)\end{array}$ & $\begin{array}{c}-0.02 \\
(0.078)\end{array}$ & $\begin{array}{c}0.015 \\
(0.082)\end{array}$ \\
\hline NTU & $\begin{array}{l}-0.206 \\
(0.200)\end{array}$ & $\begin{array}{l}-0.052 \\
(0.056)\end{array}$ & $\begin{array}{c}0.155 \\
(0.134)\end{array}$ & $\begin{array}{l}-0.030 \\
(0.223)\end{array}$ & $\begin{array}{c}0.055 \\
(0.051)\end{array}$ & $\begin{array}{l}-0.017 \\
(0.040)\end{array}$ & $\begin{array}{c}-0.177 * * * \\
(0.056)\end{array}$ & $\begin{array}{c}-0.133 * * \\
(0.058)\end{array}$ \\
\hline constant & $\begin{array}{c}6.803 * * * \\
(1.194)\end{array}$ & $\begin{array}{l}0.769 * * \\
(0.329)\end{array}$ & $\begin{array}{c}4.928 * * * \\
(0.826)\end{array}$ & $\begin{array}{l}3.136^{* * *} \\
(1.134)\end{array}$ & $\begin{array}{c}0.411 \\
(0.318)\end{array}$ & $\begin{array}{l}-0.012 \\
(0.243)\end{array}$ & $\begin{array}{c}0.920 * * * \\
(0.284)\end{array}$ & $\begin{array}{c}0.417 \\
(0.279)\end{array}$ \\
\hline $\begin{array}{l}\text { Individual Characteristics } \\
\text { Included }\end{array}$ & Yes & Yes & Yes & Yes & Yes & Yes & Yes & Yes \\
\hline P-value from F-test $(\gamma 0+\gamma 1=0)$ & $\begin{array}{c}\text { Yes } \\
0.189\end{array}$ & $\begin{array}{c}\text { Yes } \\
0.186\end{array}$ & $\begin{array}{c}\text { Yes } \\
0.933\end{array}$ & $\begin{array}{c}\text { Yes } \\
0.442\end{array}$ & 0.927 & 0.132 & 0.794 & 0.813 \\
\hline Observations & 373 & 373 & 373 & 373 & 185 & 188 & 1,865 & 1,855 \\
\hline R-squared & 0.040 & 0.037 & 0.062 & 0.049 & 0.021 & 0.046 & 0.098 & 0.069 \\
\hline
\end{tabular}


Table 9: Time Preference Parameters By Treatment Status By Schools

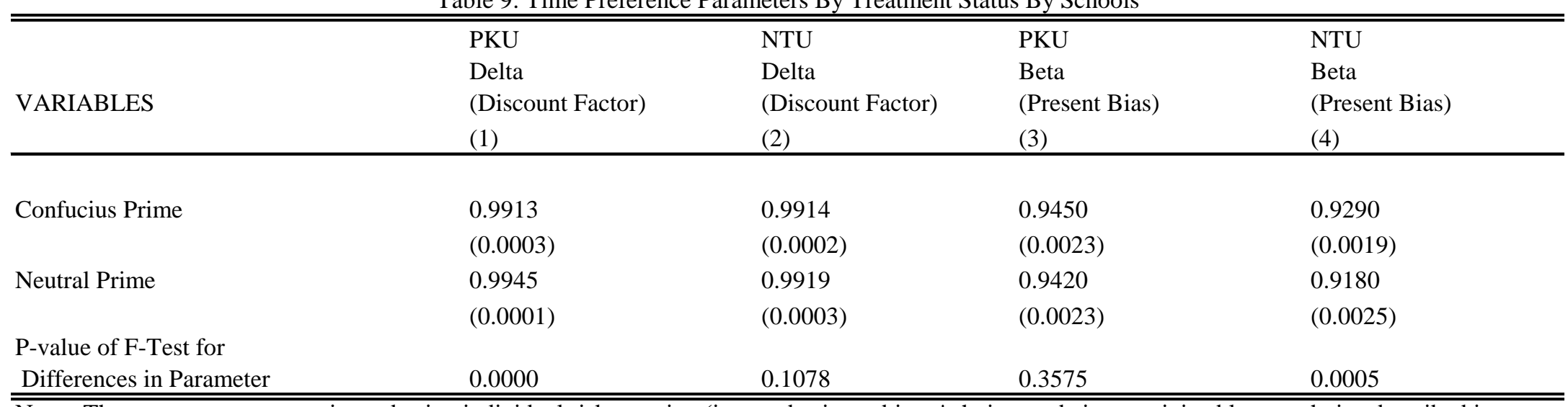

Note: These parameters are estimated using individual risk aversion (imputed using subjects' choice made in ncentivized lottery choice described in

Section 3.2) and assuming mean expenditure level at 1746 for NTU students and 1539 for PKU studentsas calculated based on the exit surve. Confucius

Prime indicates subjects receiving Confucian-salient primes and neutral prime indicates subjects receiving nuetral primes. Columns 1 and 2 report the

estimation of discount factor and columns 3 and 4 reports the estimation for present bias. Confucius Prime is a dummy for subjects receiving Confucian-

salient primes. Neutral Prime is a dummy for subjects receiving Confucian-salient primes. NTU is a dummy for subjects from National Taiwan

University. The p-value of the two-way tests of the equality of between treatments and controls group for each column is reported. 
Table 10: Validation Test of Priming Method

(1)

Ranking of

Confucianism

(1=best, $4=$ worst)
(2)

How much do you agree with

Confucianis $\mathrm{m}(10=$ most agree)
VARIABLES

\begin{tabular}{lccc} 
Confucius Prime $(\gamma 0)$ & $0.384 *$ & $-0.603 *$ & $-0.620^{* *}$ \\
Confucius Prime $* \mathrm{NTU}(\gamma 1)$ & $(0.223)$ & $(0.331)$ & $(0.278)$ \\
& $-0.463^{*}$ & $0.753 * *$ & $0.576^{*}$ \\
NTU & $(0.257)$ & $(0.381)$ & $(0.323)$ \\
& $0.460 * *$ & $-0.832^{* * *}$ & $-0.502^{* *}$ \\
& $(0.188)$ & $(0.274)$ & $(0.223)$ \\
P-value from F-test $(\gamma 0+\gamma 1=0)$ & & & 0.78 \\
Observations & 0.52 & 0.42 & 389 \\
R-squared & 389 & 386 & \\
\hline
\end{tabular}

Note: Standard errors are in parentheses. Age and gender are included in all regressions. The dependent variable in column 1 is the answer to, "Out of the 4 value systems (rationalism, Confucianism, Eastern Religion and Western Religion), please rank from 1 (being most agree with) to 4 (least agree with)." Column 1 employs an ordered probit model. We also ask "How much do you agree with Confucianism/Rationalis m/Eastern Religion/Western Religion on the scale of 1 to 10?" The dependent variable in column 2 is their rating on Confucian value minus their individual mean of evaluation of all four systems. Column 2 uses an ordinary least squares model. Column 3 uses a probit model where the dependent variable equals 1 if Confucianism is ranked as number 1.*** $\mathrm{p}<0.01, * * \mathrm{p}<0.05, * \mathrm{p}<0.1$ 


\section{References}

Afridi, F., Li, S. X., \& Ren, Y. (2012). Social Identity and Inequality: The Impact of China's Hukou System. IZA Discussion Paper No. 6417.

Alesina, A., Giuliano, P., \& Nunn, N. (2013). On the Origins of Gender Roles: Women and the Plough. The Quarterly Journal of Economics, forthcoming.

Andersen, S., Harrison, G. W., Lau, M. I., \& Elisabet Rutström, E. (2008). Lost in State Space: Are Preferences Stable. International Economic Review, 49(3), 1091-1112.

Andreoni, J., \& Sprenger, C. (2012). Estimating Time Preferences from Convex Budgets. American Economic Review, 102(7): 3333-56.

Andreoni, J., Kuhn, M. \& Sprenger, C. (2013). On Measuring Time Preferences. Working Paper.

Barr, A., \& Genicot, G. (2008). Risk Sharing, Commitment, and Information: An Experimental Analysis. Journal of the European Economic Association, 6(6), 1151-1185.

Bendix, R. (1960). Max Weber: An Intellectual Portrait. Taylor \& Francis.

Benjamin, D. J., Choi, J. J., \& Fisher, G. W. (2012). Religious Identity and Economic Behavior. National Bureau of Economic Research.

Benjamin, D. J., Choi, J. J., \& Strickland, A. J. (2010). Social Identity and Preferences. American Economic Review, 100(4), 1913-1928.

Berg, J., Dickhaut, J., \& McCabe, K. (1995). Trust, Reciprocity, and Social History. Games and Economic Behavior, 10(1), 122-142.

Brokaw, C. J. (1991). The Ledgers of Merit and Demerit: Social Change and Moral Order in Late Imperial China (p. 103). Princeton: Princeton University Press.

Buchan, N. R., Johnson, E. J., \& Croson, R. T. (2006). Let's Get Personal: An International Examination of the Influence of Communication, Culture and Social Distance on Other Regarding Preferences. Journal of Economic Behavior \& Organization, 60(3), 373-398.

Carvalho, L. Prina, S., Sydnor J. (2013), The Effects of Savings on Risk-Taking and Intertemporal Choice Behavior: Evidence from a Randomized Experiment, Working Paper.

Chan, A. (1996). Confucianism and Development in East Asia. Journal of Contemporary Asia, 26(1), 2845 .

Chung, C., Shepard, J., \& Dollinger, M. (1989). Max Weber Revisited: Some Lessons from East Asian Capitalistic Development. Asia Pacific Journal of Management, 6(2), 307-321.

Dai, H. (Ed.). (1989). Confucianism and Economic Development: an Oriental Alternative?. Washington Institute Press. 
Dijksterhuis, A., \& Bargh, J. A. (2001). "The Perception-behavior Expressway: Automatic Effects of Social Perception on Social Behavior." Advances in Experimental Social Psychology, 33, 1-40.

Elman, B. A. (1991). Political, social, and cultural reproduction via civil service examinations in late imperial China. Journal of Asian Studies, 50(1), 7-28.

Fernandez, R. (2011), Does Culture Matter?, In the Handbook of Social Economics, edited by Jess Benhabib, Matthew O. Jackson, and Alberto Bisin, pp. 481-510.

Frijters, P. , Kong, T \& Liu, E. (2013). "Who is Coming to the Experiment? A Cautionary Tale from China", Mimeo.

Gao, G. (1998). An Initial analysis of the Effects of Face and Concern for "Other" in Chinese Interpersonal Communication. International Journal of Intercultural Relation, 22, 467-482.

Giné, X., Goldberg, J. A., Silverman, D., \& Yang, D. (2012). "Revising Commitments: Field Evidence on Adjustment of Prior Choices." Unpublished.

Gorodnichenko, Y., \& Roland, G. (2013), Culture, Institutions, and theWealth of Nations." Working Paper, University of California, Berkeley

Guiso, L., Sapienza, P., \& Zingales, L. (2006). Does culture affect economic outcomes?. Journal of Economic Perspectives, 20(2), 23-48.

Hofheinz, R., \& Calder, K. E. (1982). The Eastasia Edge (pp. 41-67). New York: Basic Books.

Hofstede, G., \& Bond, M. H. (1988). The Confucius Connection: From Cultural Roots to Economic Growth. Organizational Dynamics, 16(4), 4-21.

Hofstede, G., \& Hofstede, G. J. (2005). Cultures and Organizations, Software of the Mind, Intercultural Cooperation and its Importance for Survival. Revised and expanded 2nd edition.

Holt, C. A., \& Laury, S. K. (2002). Risk Aversion and Incentive Effects. American Economic Review, 92(5), 1644-1655.

Hong, Y.-Y., Chiu, C.-Y., \& Kung, T. M. (1997). Bringing culture out in front: Effects of cultural meaning system activation on social cognition. In K. Leung, Y. Kashima, U. Kim, \& S. Yamaguchi (Eds.), Progress in Asian social psychology (Vol. 1, pp. 135-146). Singapore: Wiley

Hwang, K. (1987). Face and Favor: The Chinese Power Game. American Journal of Sociology, 944-974.

Inglehart, R., \& Baker, W. E. (2000). Modernization, cultural change, and the persistence of traditional values. American sociological review, 19-51.

Ip, P. K. (2009). Is Confucianism Good for Business Ethics in China? Journal of Business Ethics, 88(3), 463-476.

Kahn, H. (1979). World Economic Development: 1979 and Beyond. CO: Westview. 
Knack, S., \& Keefer, P. (1997). Does Social Capital Have an Economic Payoff? A Cross-country Investigation. Quarterly Journal of Economics, 112(4), 1251-1288.

Koehn, D. (2001). Confucian Trustworthiness and the Practice of Business in China. Business Ethics Quarterly, 11(3), 415-429.

Laibson, D. (1997). Golden Eggs and Hyperbolic Discounting. Quarterly Journal of Economics, 112(2), 443-478.

Lam, K. J. (2003). Confucian Business Ethics and the Economy. Journal of Business Ethics, 43(1/2, Business Ethics in the Global Knowledge Economy), 153-162.

Liang, M. (2010). Confucianism and the East Asian Miracle. American Economic Journal: Macroeconomics, 2(3), 206-234.

Liu, E. (2013). Time to Change What to Sow: Risk Preferences and Technology Adoption Decisions of Cotton Farmers in China, Review of Economics and Statistics, Forthcoming,.

Legge, J. (1893). The Chinese Classics with a Translation, Critical and Exegetical Notes, Prolegomena, and Copious Indexes: Confucian Analects, the Great Learning, and the Doctrine of the Mean (Vol. 1). Revised second edition (1893), Oxford: Clarendon Press,

Lu, X. (2004). Rhetoric of the Chinese Cultural Revolution: The Impact on Chinese Thought, Culture, and Communication. Univ of South Carolina Press.

Macrae, C. N., \& Johnston, L. (1998). Help, I Need Somebody: Automatic Action and Inaction. Social Cognition, 16(4), 400-417.

Nunn, N., \& Wantchekon, L. (2011). The Slave Trade and the Origins of Mistrust in Africa. American Economic Review, 101, 3221-3252.

Mayer, J. D., Schmidt, H. M. (2004). Gendered political socialization in four contexts: political interest and values among junior high school students in China, Japan, Mexico, and the United States. Social Science Journal, 41(3), 393-407.

Morris, M. W., Nisbett, R. E., \& Peng, K. (1995). Causal attribution across domains and cultures. In D. Sperber, D. Premack, \& A. J. Premack (Eds.), Causal cognition: A multidisciplinary debate (pp. 577-612). Oxford, England: Clarendon Press.

Ornatowski, G. K. (1996). Confucian Ethics and Economic Development: A Study of the Adaptation of Confucian Values to Modern Japanese Economic Ideology and Institutions. Journal of SocioEconomics, 25(5), 571-590.

La Porta, R., Lopez-de-Silanes, F., Shleifer, A., \& Vishny, R. W. (1997). Trust in Large Organizations. American Economic Review, 87(2), 333-338.

Rozman, G. (1992). "The Confucian faces of capitalism." Pacific Century: The Emergence of Modern Pacific Asia, 308-316. 
Shaw, K. L. (1996). An Empirical Analysis of Risk Aversion and Income Growth. Journal of Labor Economics, , 626-653.

Tan, H. H., \& Chee, D. (2005). Understanding Interpersonal Trust in a Confucian-influenced Society An Exploratory Study. International Journal of Cross Cultural Management, 5(2), 197-212.

Tanaka, T., C. F. Camerer, and Q. Nguyen. (2010). Risk and Time Preferences: Linking Experimental and Household Survey Data from Vietnam. American Economic Review, 100(1): 557-71.

Tse, D. K. (1996). Understanding Chinese People as Consumers: Past Findings and Future Propositions. In M. H. Bond (Ed.), The Handbook of Chinese psychology. Hong Kong: Oxford University Press.

Turner, J. C. (1985). Social Categorization and the Self-concept: A Social Cognitive Theory of Group Behavior. Advances in Group Processes: Theory and Research, 2, 77-122.

Wheeler, S. C., \& Berger, J. (2007). When the Same Prime Leads to Different Effects. Journal of Consumer Research, 34(3), 357-368.

Wheeler, S. C., Jarvis, W. B. G., \& Petty, R. E. (2001). Think unto others: The self-destructive impact of negative racial stereotypes. Journal of Experimental Social Psychology, 37(2), 173-180.

Yeh, Q., \& Xu, X. (2010). The Effect of Confucian Work Ethics on Learning About Science and Technology Knowledge and Morality. Journal of Business Ethics, 95(1), 111-128. 